University of Nebraska - Lincoln

DigitalCommons@University of Nebraska - Lincoln

Publications, Agencies and Staff of the U.S.

Department of Commerce

U.S. Department of Commerce

2012

Prototype for monitoring and forecasting fall foliage coloration in real time from satellite data

Xiaoyang Zhang

NOAA/NESDIS/STAR, Xiaoyang.zhang@noaa.gov

Mitchell D. Goldberg

NOAA/NESDIS/STAR

Yunyue Yu

NOAA/NESDIS/STAR

Follow this and additional works at: https://digitalcommons.unl.edu/usdeptcommercepub

Part of the Environmental Sciences Commons

Zhang, Xiaoyang; Goldberg, Mitchell D.; and Yu, Yunyue, "Prototype for monitoring and forecasting fall foliage coloration in real time from satellite data" (2012). Publications, Agencies and Staff of the U.S. Department of Commerce. 361.

https://digitalcommons.unl.edu/usdeptcommercepub/361

This Article is brought to you for free and open access by the U.S. Department of Commerce at DigitalCommons@University of Nebraska - Lincoln. It has been accepted for inclusion in Publications, Agencies and Staff of the U.S. Department of Commerce by an authorized administrator of DigitalCommons@University of Nebraska - Lincoln. 


\title{
Prototype for monitoring and forecasting fall foliage coloration in real time from satellite data
}

\author{
Xiaoyang Zhang ${ }^{\mathrm{a}, *}$, Mitchell D. Goldberg ${ }^{\mathrm{b}}$, Yunyue Yu ${ }^{\mathrm{b}}$ \\ a Earth Resources Technology Inc at NOAA/NESDIS/STAR, 5825 University Research Ct., College Park, MD 20740, United States \\ ${ }^{\mathrm{b}}$ NOAA/NESDIS/STAR, 5200 Auth Road, Camp Springs, MD 20746, United States
}

\section{A R T I C L E I N F O}

\section{Article history:}

Received 24 August 2011

Received in revised form

28 December 2011

Accepted 14 January 2012

\section{Keywords:}

Phenology

Fall foliage coloration

Foliage phase

Time-series satellite data

Temporally-normalized brownness index

Real-time monitoring

Short-term forecasting

\begin{abstract}
A B S T R A C T
While determining vegetation phenology from the time series of historical satellite data has been widely investigated throughout the last decade, little effort has been devoted to real-time monitoring and shortterm forecasting. The latter is more important for numerical weather modeling, ecosystem forecasting, forest and crop management, and health risk warning. In this study we developed a prototype approach for the real-time monitoring and short-term forecasting of fall foliage status (including low coloration, moderate coloration, near-peak coloration, peak coloration, and post-peak coloration) using temporal satellite observations. The algorithm combined the climatology of vegetation phenology and temporally available satellite observations to establish a set of potential temporal trajectories of foliage development at a given time. These trajectories were used to identify foliage coloration phases in real time, to predict the occurrence of future phenological events, and, furthermore, to analyze the uncertainty of monitoring and forecasting. With an increase in satellite observations, monitoring and forecasting were continuously updated. The approach developed was tested using MODIS (Moderate Resolution Imaging Spectroradiometer) data at a spatial resolution of $500 \mathrm{~m}$ across northeastern North America and evaluated using field measurements at the Harvard Forests of the northeastern United States and standard MODIS foliage coloration phases. The results indicate that short-term forecasting can be well implemented in more than half a month before the occurrence of a foliage phase, and that the accuracy of the real-time monitoring of both near-peak-coloration and peak-coloration occurrence is less than 5 days in most mixed forests and deciduous forests.
\end{abstract}

(c) 2012 Elsevier B.V. All rights reserved.

\section{Introduction}

Vegetation phenology is an important parameter in regional and global modeling, ecological monitoring, and climate change detection. Shifts in phenology reflect interactions among the terrestrial biosphere, the atmosphere, and the hydrosphere, including nutrient dynamics, photosynthesis, water cycling, soil moisture depletion, transpiration, and canopy physiology (Herwitz, 1985; Myneni et al., 1997; Schwartz, 1998; Asner et al., 2000; Parmesan and Yohe, 2003).

As reported in IPCC (2007), vegetation phenology (including shifts in the timing of bud burst, leaf development, senescence, and length of growing season) is one of the simplest and most effective indicators of climate change. Long-term phenology records of both field measurements and satellite observations have revealed that mean spring vegetation leaf greenup has advanced with a rate of 2-4 days per decade in mid-high latitudes because of the

\footnotetext{
* Corresponding author.

E-mail address: Xiaoyang.zhang@noaa.gov (X. Zhang).
}

increase in temperature associated with anthropogenic greenhouse effects (Parmesan and Yohe, 2003; Myneni et al., 1997; Zhang et al., 2007), whereas vegetation greenup onsets have become delayed in middle-low latitudes (Zhang et al., 2007). The variation in phenology also provides evidence of the large-scale climatic features associated with El Nino cycles (Myneni et al., 1997; Asner and Townsend, 2000), precipitation, and drought (Zhang et al., 2005, 2010; Huete et al., 2006).

Near real-time monitoring and short-term forecasting of vegetation phenology, on the other hand, have a wide social, cultural, and economic significance to people on this planet, including for food supply, human health, species invasions, droughts, and disease outbreaks (White and Nemani, 2006). They are particularly important in assisting (1) farmers for predicting the optimum timing for cultivation practices and for monitoring drought occurrences and crop germination (e.g. Hartkamp et al., 2002; Keatinge et al., 1998; Atkinson and Porter, 1996); (2) foresters for detecting disturbances related to hurricane destruction, forest pests, disease outbreaks, and species invasion (Gu et al., 2008; McNulty, 2002; Chambers et al., 2007); (3) human health managers for providing short-term forecasts of the critical timing of allergenic pollen 
occurrences and duration (Karlsen et al., 2009); (4) environmental and weather modelers for the accurate modeling of seasonal carbon sequestration and land-surface physical properties; and (5) tourists for seeing spring wildflowers and fall foliage colors.

During the last decade, various methods were developed to detect the timing of phenological events of vegetation at regional and global scales using AVHRR (Advanced Very High Resolution Radiometer) and MODIS (Moderate Resolution Imaging Spectroradiometer) data (e.g. Reed et al., 1994; White et al., 1997; Zhang et al., 2003; Jonsson and Eklundh, 2004). These efforts mainly focused on the development of historical phenology data using a year-long time series of satellite data covering past vegetation growth cycles. This was due to the fact that the time series of remotely sensed data are generally noisy because of cloudy and atmospheric contaminations, and that the vegetation index in a given date needs to be smoothed using observations in preceding and succeeding days for the detection of phenology. The uncertainties in satellite data make the monitoring of vegetation phenology in real time extremely challenging. As a result, very few methods have been developed for the near real-time monitoring and short-term forecasting of vegetation phenology from satellite data, although phenology forecasting has been investigated using a vegetation index threshold in a specific ecoregion (White and Nemani, 2006) and by integrating satellite data, microclimate mapping, and ecosystem simulation models (Nemani et al., 2009).

This paper proposes a prototype algorithm for monitoring and forecasting fall foliage coloration phases in individual satellite pixels. The algorithm was first used to calculate the climatology of vegetation phenological development based on historical satellite data. Combining phenologic climatology and available satellite observations at the time of monitoring, a set of potential temporal trajectories for a senescent phase were then simulated. These potential trajectories were used to identify foliage coloration phases in real time, to predict the occurrence of near future phenological events, and to analyze the uncertainty of real-time monitoring and short-term forecasting. The monitoring and forecasting were continuously implemented with an increase in near real-time satellite observations during the senescent phase. The approach proposed was tested using MODIS data across northeastern North America (MODIS land tile of horizontal 12 and vertical 4, $40^{\circ}-50^{\circ} \mathrm{N}$ and $\left.-65.3^{\circ}-93.3^{\circ} \mathrm{W}\right)$.

\section{Methodology}

Fig. 1 describes the flowchart of the algorithm used to monitor and forecast fall foliage coloration status using the satellite data. The algorithm basically consists of climatology generation, potential trajectory simulation, foliage coloration phase detection, and uncertainty analysis. The implementation of monitoring from satellite data is continuously conducted during the period of foliage development. The prediction before the occurrence of a phenological event is here called "short-term forecasting", while detection around the phenological occurrence is called "real-time monitoring". After the occurrence of a coloration status, the coloration detection is defined as "near real-time monitoring".

\subsection{Data sets for algorithm development and testing}

Both the satellite data and field measurements were obtained to develop and evaluate the algorithm for monitoring and forecasting fall foliage coloration phases. First, we collected a time series of MODIS data from 2001 to 2008 in northeastern North America (MODIS land tile $\mathrm{H} 12 \mathrm{~V} 04,40^{\circ}-50^{\circ} \mathrm{N}$ and $-65.3^{\circ}-93.3^{\circ} \mathrm{W}$ ). Specifically, the MODIS BRDF (bi-directional reflectance distribution function)/albedo product (MCD43A4, collection 5) produces the
Nadir BRDF Adjusted Reflectance (NBAR) using a semi-empirical, kernel-driven reflectance anisotropy model and multi-day, cloudfree, and atmospherically-corrected surface reflectance from EOS-Aqua and EOS-Terra satellite data (Schaaf et al., 2002). This product is produced every 8 days (based on the last 16 days of observations) at a spatial resolution of $500 \mathrm{~m}$. The corresponding BRDF Albedo Quality (MCD3A2) product provides a snow and ice flag in its Quality Assurance (QA) field (Schaaf et al., 2002; Román et al., 2009). We calculated a time series of NDVI from 8-day NBAR data in each pixel. This NBAR NDVI dataset is temporally and spatially consistent and comparable.

The MODIS land surface temperature (LST) product was used to determine the winter period in which the NDVI variation reflects abiotic influences. The LST product (MOD11A2, collection 5) produces estimates of the surface skin temperature for an 8-day time period by averaging the daily LST measurements with a spatial resolution of $1 \mathrm{~km}$ (Wan et al., 2002). The time series of LST for each pixel in this study was generated by replacing any missing values by using a moving arithmetic average of the nearest preceding and subsequent values. It was then simply re-sampled to a spatial resolution of $500 \mathrm{~m}$ by using a nearest neighbour approach in order to match the MODIS NBAR data. Note that the approaches in spatial re-sampling and temporal replacement of missing values were simple and not necessary to provide highly accurate LST data. However, the resultant LST data allowed us to determine the winter periods when snow cover could appear and further to distinguish the irregular NDVI values that could be contaminated by snow cover during a vegetation dormant stage.

The MODIS land cover product (collection 5), at a spatial resolution of $500 \mathrm{~m}$, was used to stratify ecosystem types for analyzing any phenological detections. This product provides 17 land-cover classes following the International Geosphere-Biosphere Program (IGBP) scheme (Friedl et al., 2010). Land cover types in the study region mainly consist of evergreen needleleaf forests, deciduous broadleaf forests, mixed forests, croplands, and croplands and natural vegetation mosaic.

Secondly, we collected field measurements of fall foliage developments in the Harvard Forest from 2001 to 2008 to verify MODIS monitoring. The Harvard Forest is a long-term ecological reserve (LTER) site located at $42^{\circ} 32^{\prime} \mathrm{N}$ and $72^{\circ} 11^{\prime} \mathrm{W}$ (http://www.lternet.edu/hfr/). This site records leaf development in 33 woody species representing most species of both overstory and understory individuals. The fall foliage observations included the percentage of leaves that changed color on a given tree and the percentage of leaves that fell at 3- to 7-day intervals during the autumn.

\subsection{Generation of climatology of vegetation phenology}

The climatology of the vegetation phenology was derived from MODIS data over the past eight years between 2001 and 2008 Phenological metrics were retrieved from an annual time series of NBAR NDVI data using an approach developed by Zhang et al. (2003). Briefly, the background NDVI in a time series was determined by selecting the 75 percentiles of NDVI values that were not contaminated by snow during a winter period (LST $<278 \mathrm{~K}$ ). The background NDVI was used to replace the irregular NDVI values that were mainly contaminated by snow cover during winter. The cloud-contaminated data were replaced using a moving-window average based on two nearest neighbors with valid data. The annual time series of NDVI data for each individual pixel were then fitted against the day of year (DOY) using a sigmoidal model of vegetation growth (Zhang et al., 2003):

$y_{(t)}=\frac{c}{1+e^{a+b t}}+d$ 


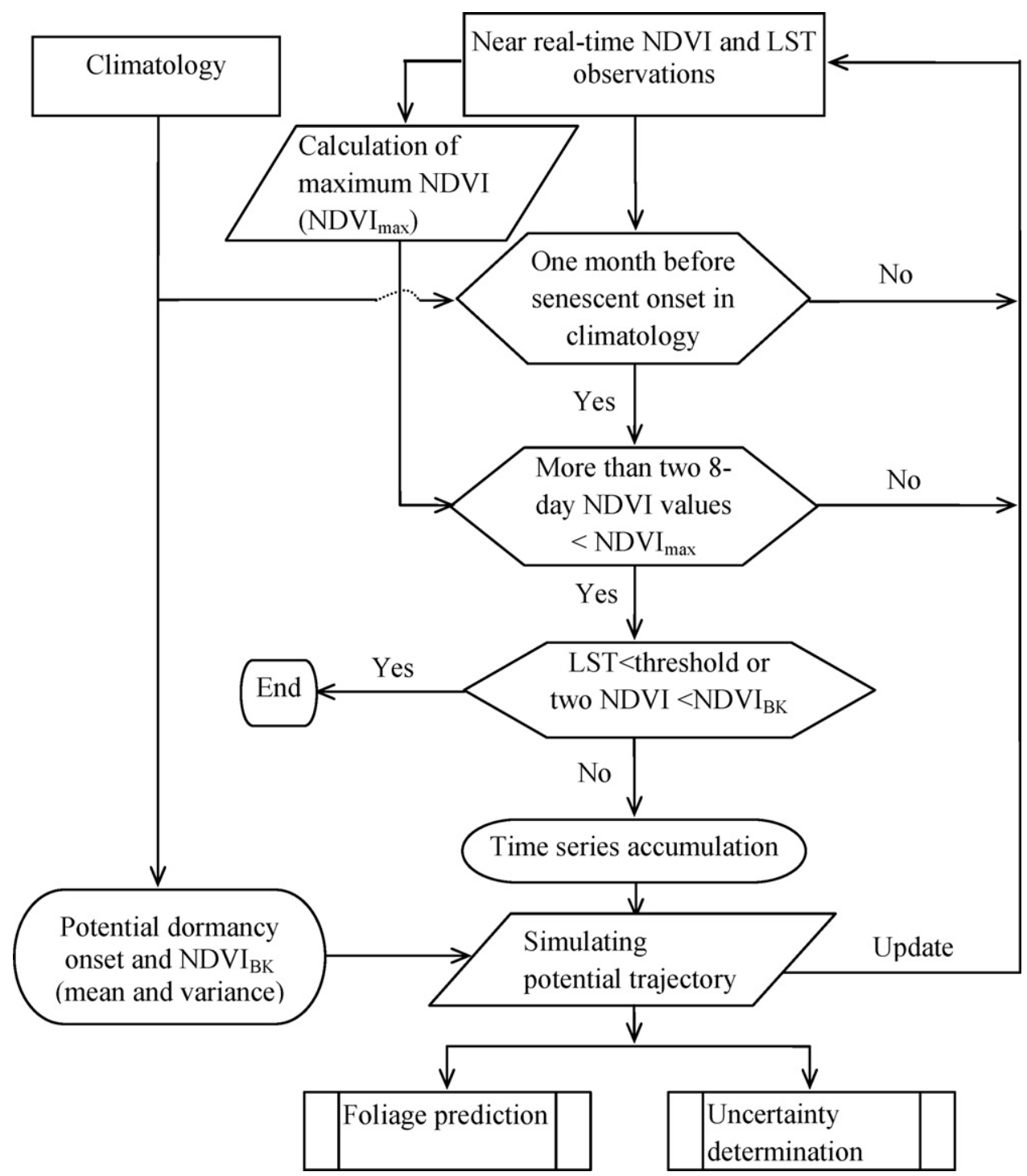

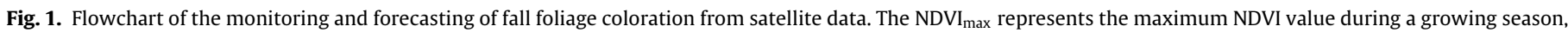
$\mathrm{NDVI}_{\mathrm{BK}}$ is the minimum NDVI without snow and cloud contamination in a given pixel, and LST is land surface temperature.

where $t$ is time in days, $y_{(t)}$ is the NDVI value at time $t, a$ and $b$ are parameters characterizing the rate of development of senescence, $c+d$ is the maximum NDVI value, and $d$ is the initial background NDVI value.

The curvature change rate along the modeled curve was then calculated to automatically detect the phenological transition dates. During a senescent phase, two minimum values of the curvature change rate were corresponding to the timing of senescent onset and the timing of dormancy onset, separately (Zhang et al., 2003). The maximum NDVI, the NDVI value at dormancy onset, and the background NDVI value were calculated from the sigmoidal model in this study.

Using the phenological metrics from 2001 to 2008, we calculated the climatology of vegetation phenology, which represents the potential range of senescent variations. The climatological parameters were described using the mean value (MV) and standard deviation (SD) for the metrics separately that were the timing of senescent onset and dormancy onset, maximum NDVI, NDVI value at dormancy onset, and background NDVI.

\subsection{Simulation of potential senescent trajectories}

In the implementation of real/near real-time monitoring and short-term forecasting, potential NDVI trajectories in a senescent phase were simulated using the available NDVI data at a given time. With the accumulation of raw NBAR NDVI data (without smoothing) during the development of fall foliage, the algorithm practically started one month before the climatological timing of senescence onset. By gradually chasing all available 8-day MODIS NBAR NDVI data in a given phenological cycle, it was assumed that the peak of a vegetation cycle would be detected. Once there were two smaller 8-day NDVI values following the occurrence of maximum NDVI, which was at time P1 in Fig. 2, the NDVI observations following the occurrence of the maximum NDVI were recorded. These available NDVI observations were not sufficient in order to establish a temporal trajectory of senescent foliage variation using the sigmoidal model (Eq. (1)), so we employed the climatological conditions of dormancy characteristics as the potential foliage development. The climatological characteristics used here were the 


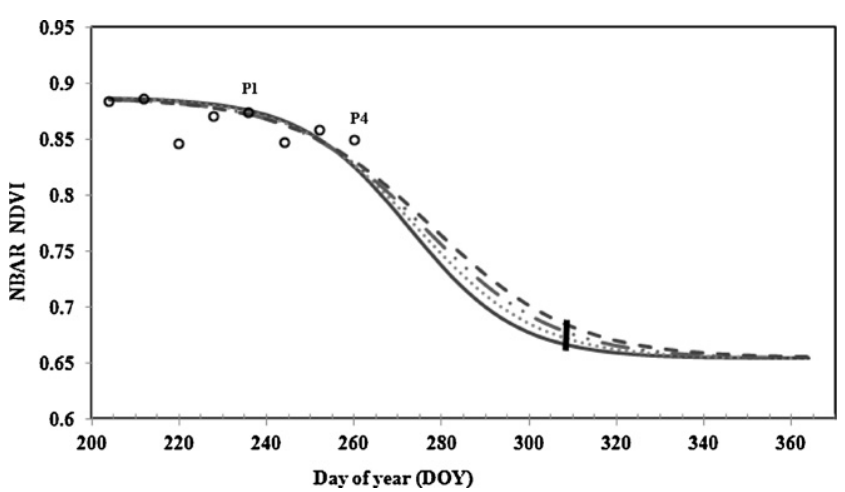

Fig. 2. Simulating potential NDVI trajectories of a senescent phase in near real time for a pixel. The circles are the NBAR NDVI data available at the time of simulating the temporal trajectories. The black bar represents the potential range of NDVI values at the climatological timing of dormancy onset. The trajectories were calculated from the available data (before time P4) and the climatological NDVI at the onset of dormancy. Similarly, the potential trajectory varied with the uncertainty of background NDVI and timing of dormancy onset, which is not presented in this figure.

background NDVI, and both the NDVI value and timing at dormancy onset.

A set of potential temporal trajectories were simulated using the sigmoidal model at the time of each NBAR NDVI observation by combining the potential NDVI value, the timing at dormancy onset, and the potential background NDVI value. The potential values that were determined according to climatology were as follows: the NDVI value increased by 0.002 between MV-SD and MV+SD and the timing of dormancy onset increased by one day within the climatological range. Thus, a set of potential trajectories was generated at a given time, such as P4 in Fig. 2. These trajectories were updated with the increase of each NBAR NDVI observation in real time, and the simulated trajectory gradually approached the actual temporal pattern.

\subsection{Determination of fall foliage coloration phases}

The coloration phases of fall foliage were continuously monitored and predicted from the potential temporal trajectories with increasing NDVI observations. Specifically, the simulated potential trajectories were further used to derive the temporally-normalized brownness index (TNBI). This index describes the relative dynamics of the fraction of colored foliage and is independent of the surface background, vegetation abundance, and species composition. It is expressed in the following formula (Zhang and Goldberg, 2011):

$T N B I_{b(t)}=1-\frac{1}{1+e^{a+b t}}$

where $T N B I_{b(t)}$ is the temporally-normalized brownness index at time $t$, and $a$ and $b$ are the parameters characterized by leaf development in an individual pixel. These two parameters in each pixel were obtained from the potential senescent trajectory simulated using the sigmoidal model, as described in Section 2.3. The temporally-normalized brownness index was assumed to be capable of describing the dynamics of relative fall foliage coloration in each individual pixel because the sigmoidal model has been applied to model seasonal trajectory of vegetation growth across various ecosystems over the globe using webcam data (Richardson et al., 2006; Kovalskyy et al., 2012), Landsat TM data (e.g. Fisher et al., 2006; Kovalskyy et al., 2012), AVHRR data (e.g. Zhang et al., 2007), and MODIS data (e.g. Zhang et al., 2003, 2006; Liang et al., 2011).

The temporally-normalized brownness index is a function of foliage coloration status (Zhang and Goldberg, 2011). According to the percentage of colored foliage, the brownness index was used to categorize the fall foliage coloration into five phases that are low coloration, moderation coloration, near-peak coloration, peak coloration, and post-peak coloration. These phases are corresponding to the brownness index of $<0.2,0.2-0.4,0.4-0.6,0.6-0.85$, and $0.85-1$, respectively.

Monitoring and forecasting of foliage coloration phases were finally obtained from the trajectories of potential brownness index. At any given time, we generally simulated about 5000 potential curves of brownness index for a pixel with variations in the climatological parameters. From these curves, we calculated a set of estimates for foliage coloration status. The mean value of the estimates was considered to be the prediction and the standard deviation was taken as the uncertainty of the prediction.

\subsection{Assessment of monitoring and forecasting fall foliage coloration}

The accuracy of monitoring and forecasting was assessed by comparing predictions with field measurements and reference MODIS detections, separately. The field data in the Harvard Forest were used to match with MDOIS measurements to verify the MODIS capacity of monitoring foliage coloration statuses. Because satellite observes foliage dynamics in an entire pixel, we calculated the average fraction of foliage cover at each observation time. The numerical average could realistically represent the foliage status in the vegetation community although it would be more appropriate to calculate the foliage phase based on the areal average if the percent area of each species (overstory and understory) were known.

The temporal percentage of colored leaves measured in the Harvard Forest was further fitted using a sigmoidal model of vegetation growth (e.g. Ratkowsky, 1983; Zhang et al., 2003) to quantify the occurrences of foliage coloration. The model smoothened out uncertainties in the field measurements and allowed us to continuously calculate the percentage of the color foliage. According to the percentage of colored leaves, fall foliage coloration phases were then defined as the followings (Zhang and Goldberg, 2011): low coloration ( $<21 \%$ colored leaves), moderate coloration $(21-42 \%$ colored leaves), near-peak coloration (42-63\% colored leaves), peak coloration (63-90\% colored leaves), and post-peak coloration (90-100\% colored leaves). The occurrences of these field fall foliage phases were used to compare the monitoring and forecasting of fall foliage coloration phases derived from MODIS data between 2001 and 2008 using absolute mean difference (AMD).

Across the northeastern North American region (one MODIS land tile), the standard MODIS detection of foliage coloration phases was used as a reference to assess the forecasting and monitoring of fall foliage coloration phases in 2005. The development of standard MODIS detection foliage coloration phases was presented by Zhang and Goldberg (2011) and is briefly described here. A year-long time series of MODIS NDVI in a pixel was smoothed and functionalized using the sigmoidal model to depict the continuous dynamics of vegetation growth. The modeled temporal NDVI trajectory during the senescent phase was further combined with the mixture modeling of surface components to deduce the temporally-normalized brownness index. This brownness index was quantitatively linked with the fraction of colored and fallen leaves which were applied to classify the fall foliage coloration phases.

\section{Results}

\subsection{Monitoring and forecasting of fall foliage coloration in the Harvard Forest}

Fig. 3 presents the temporal development of colored leaves, fitted using a sigmoidal model based on the field measurements. It 


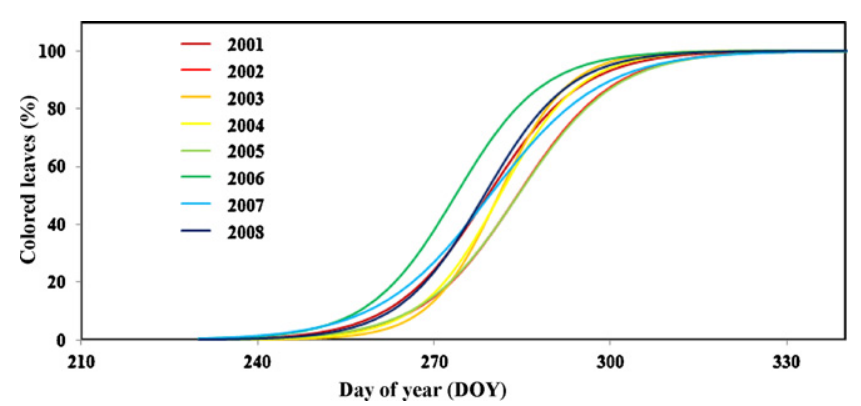

Fig. 3. Fitted temporal curves of colored foliage measured in the field of the Harvard Forests.

is revealed that the model-fitted curves of colored foliage realistically represent the field measurements with a regression slope of $1.008 \pm 0.016$, a coefficient of determination $\left(R^{2}\right)$ of $0.995 \pm 0.0037$, and an RMSE (root mean square error in percentage leaves) of $2.66 \pm 1.09$ between 2001 and 2008. The curves are very similar for the years 2003 and 2004 and the years 2002 and 2005, whereas the curves greatly shift in some of the other years. For example, the time shift of the curves between 2002 (or 2005) and 2006 is about 10 days. Correspondingly, the fall foliage coloration status clearly varied during the period from 2001 to 2008, where the difference in the timing of peak coloration onset could be as large as 11 days (Fig. 4). Indeed, these field-measured foliage coloration phases were good representatives of ground truth for validating the satellite monitoring and forecasting.

Compared with the field measurements in the Harvard Forests, the accuracy of monitoring and forecasting foliage coloration using MODIS NDVI data varied with both the foliage coloration phases and the availability of satellite observations. On average, for the 8 years (2001-2008), the absolute mean error in monitoring and forecasting decreased with the increase in MODIS data observations (Fig. 5). The error was 7 days and 10 days at low and moderate coloration, respectively, when forecasting was conducted at about half a month before the phenological events. It was reduced to 5 and 7 days, respectively, when monitoring was implemented around the time of the event occurrence. In contrast, the coloration occurrences of near peak, peak, and post-peak colorations were well predicted from MODIS data with an error of less than 5 days in half a month earlier and with an error of about 2 days in real time.

Generally, the error was large when monitoring low and moderate colorations because of the limited satellite observations that were available, whereas it was considerably reduced for the nearpeak coloration and peak coloration. The accuracy increased with the estimates made at the time approaching the occurrence of a phenological event. When model estimates were made around the occurrence of phenological events (real time), the accuracy greatly improved (Fig. 5).

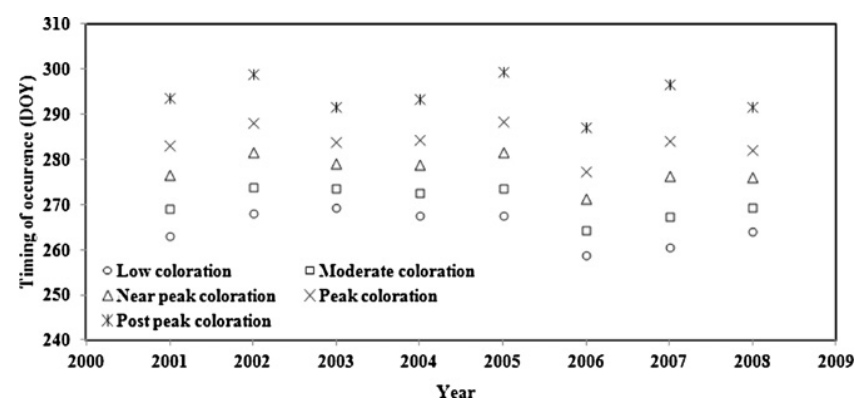

Fig. 4. Onset of the foliage coloration phases derived from field measurements in the Harvard Forests.

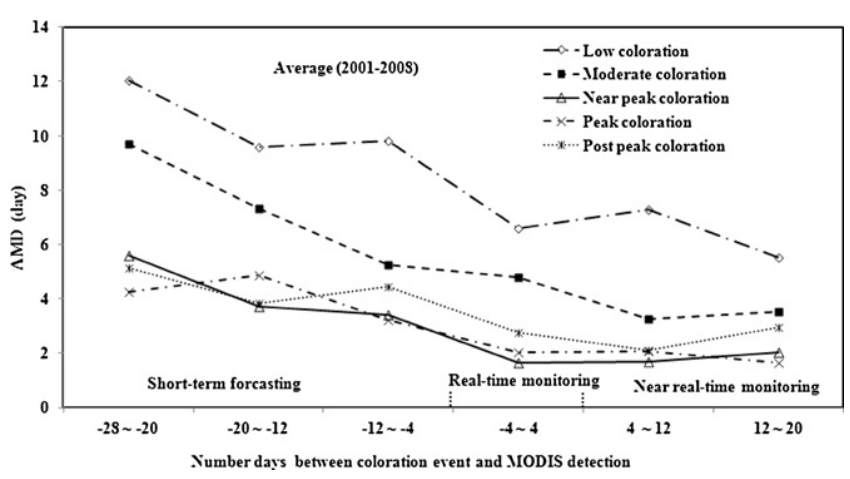

Fig. 5. Average absolute mean errors of foliage coloration monitoring and forecasting in the Harvard Forests during 2001-2008. The $Y$-axis defines absolute mean errors of MODIS detections compared with the field measurements and the $X$-axis represents the different time ranges between MODIS detection implementation and the occurrence of coloration phase onset measured in field. Negative values represent the implementation of MODIS detection before event occurrence (forecasting), while positive values indicate monitoring after event occurrence (near real time). The MODIS detection conducted within 4 days before and after the coloration event is termed real-time monitoring.

Uncertainty in the monitoring and forecasting also decreased with an increase in MODIS NDVI observations in the Harvard Forest (Fig. 6). The uncertainty was relatively large when forecasting low coloration occurrence, whereas it was small when forecasting near-peak coloration and peak coloration. The average uncertainty between 2001 and 2008 was about 3-4 days when forecasting was conducted about half a month before the corresponding coloration event, except for the low coloration occurrence, and it was 1.7-2.4 days in real-time monitoring (within 4 days of coloration event occurrence). The uncertainty was generally less than 2 days in near real-time monitoring (after the occurrence of coloration events), except for the post-peak coloration. These patterns of uncertainty were most likely associated with the fact that climatological parameters play an important role in simulating potential temporal trajectories in the early stage of a senescent phase. However, with the increase in satellite observations, the influence of climatology was gradually reduced.

\subsection{Real-time monitoring of fall foliage coloration over northeastern North America}

Only the spatial pattern in the real-time monitoring is presented here to illustrate the performance of the algorithm, although monitoring and forecasting were implemented every 8 days with the

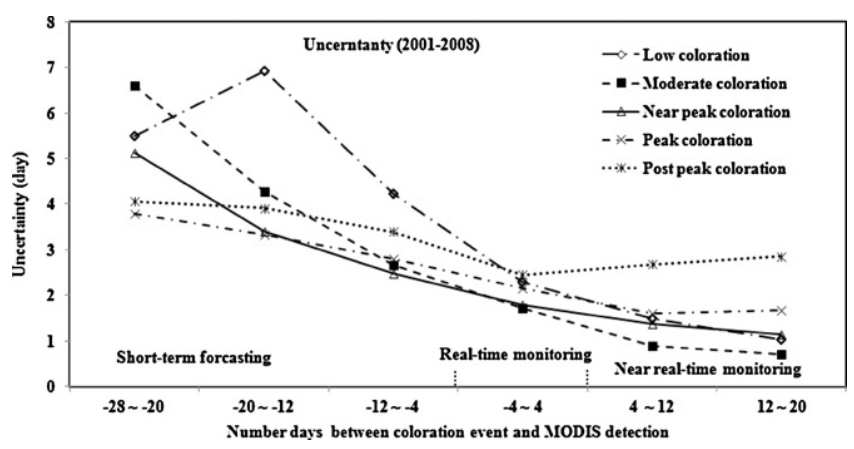

Fig. 6. Uncertainty of the monitoring and forecasting of fall foliage coloration in the Harvard Forests during 2001-2008. The $Y$-axis represents the uncertainty of MODIS detections, which is the average standard deviation from 2001 to 2008 . The $X$-axis represents the different time ranges between MODIS detection implementation and the coloration phase onset measured in the field. Negative values represent the implementation of MODIS detection before event occurrence, while positive values represent after event occurrence. 

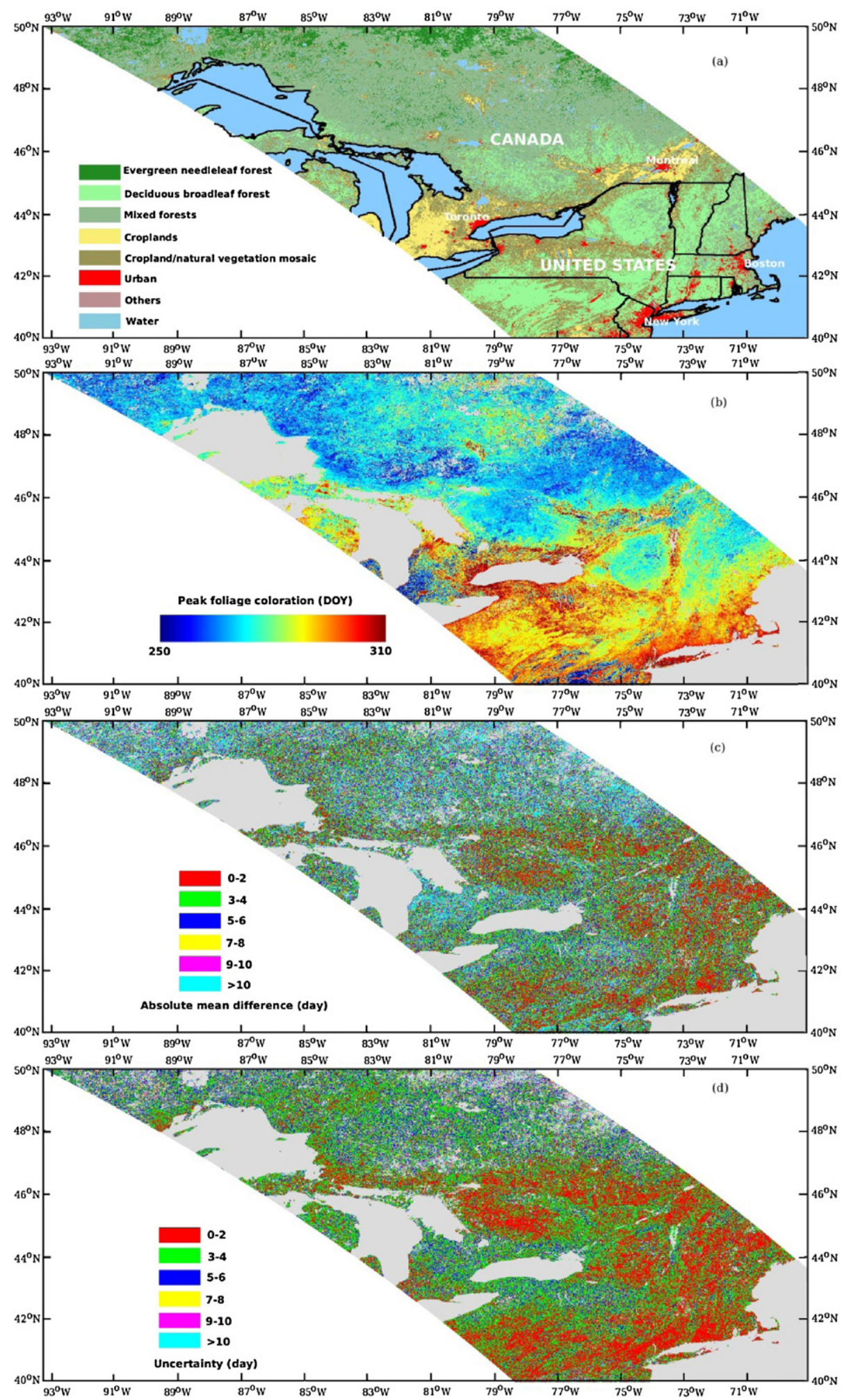

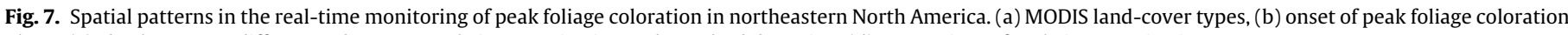
phase, (c) absolute mean differences between real-time monitoring and standard detection, (d) uncertainty of real-time monitoring.

increase in MODIS NBAR observations over northeastern North America region in 2005. Fig. 7 shows the spatial pattern in the real-time monitoring of peak foliage coloration across the research region, where the land pixels consist of $6.3 \%$ evergreen forests, $24.4 \%$ deciduous forests, $41.4 \%$ mixed forests, $6.6 \%$ croplands, and $20.4 \%$ cropland and natural vegetation mosaics (Fig. 7a). The peak coloration occurred in September in northern areas, gradually shifting southwards, and reaching southern areas around $40^{\circ} \mathrm{N}$ in late October (Fig. 7b). Note that foliage coloration was not detected in some evergreen forests where there were very limited or no deciduous trees.

Fig. 7c shows the absolute mean difference (AMD) between the real-time monitoring and the reference MODIS detection of peak coloration occurrence. The difference was mainly around 5-10 days 

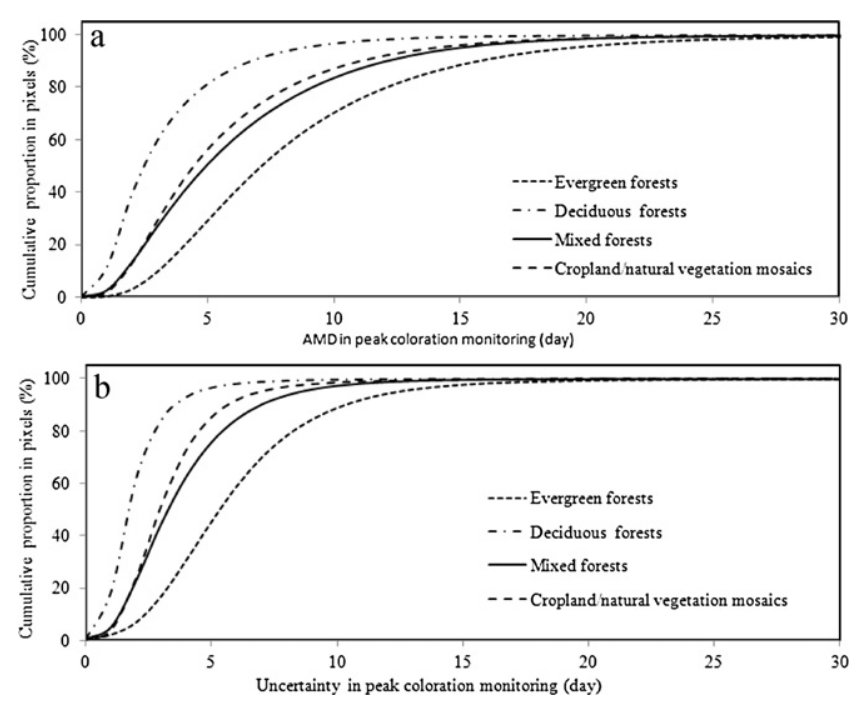

Fig. 8. Pixel $(500 \mathrm{~m})$ frequency of uncertainty in the real-time monitoring of the onset of peak foliage coloration in various ecosystems. (a) Absolute mean difference (AMD) between real-time monitoring and standard detection, and (b) uncertainty of real-time monitoring.

in the northern region (where mixed forests dominate) whereas it was generally less than 5 days in the southern regions (mainly covered by deciduous forests). Specifically, the AMD was less than 5 days in $81 \%$ of deciduous pixels and less than 10 days in $84 \%$ of mixed forests, $87 \%$ of cropland and natural vegetation mosaics, and $71 \%$ of evergreen forests (Fig. 8a).

Fig. 7d illustrates the spatial variation in uncertainty of the realtime monitoring of peak coloration occurrence. The uncertainty was generally less than 2 days and less than 4 days in deciduous and mixed forests, respectively. In contrast, the uncertainty was slightly larger in the other ecosystems. The pixel histogram revealed that the uncertainty of detection was less than 5 days in $97 \%$ of the deciduous forests, $76 \%$ of mixed forests, 85 of crop and natural vegetation mosaics, and $45 \%$ of the evergreen forests (Fig. $8 \mathrm{~b}$ ).

The accuracy of real-time monitoring varied in various coloration phases. The AMD in both deciduous forests and mixed forests varied considerably when monitoring different coloration phases (Fig. 9a). The AMD was largest when monitoring low
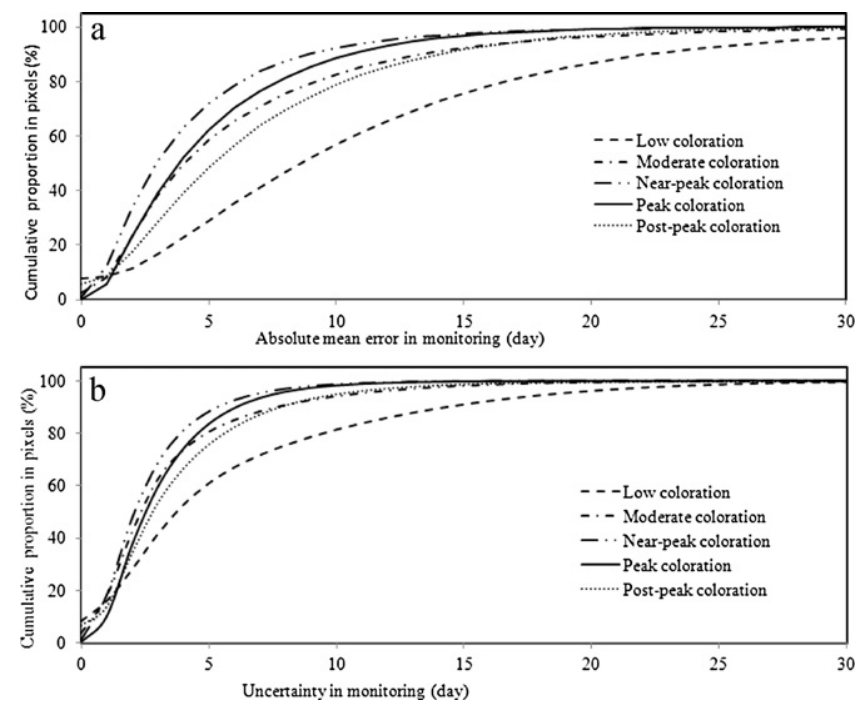

Fig. 9. Pixel (500 m) frequency of uncertainty in real-time monitoring at various coloration phases in deciduous forests and mixed forests. (a) Absolute mean difference and (b) uncertainty. coloration, which was less than 10 days in $57 \%$ of pixels. This was followed by post-peak coloration, which was less than 5 days and 10 days in $49 \%$ and $79 \%$ of pixels, respectively. The accuracy of monitoring was high for the onset of moderate, near-peak, and peak coloration phases. The AMD was less than 5 days and 10 days in more than $60 \%$ and $90 \%$ of pixels, respectively, in near-peak and peak coloration phases.

Similarly, the uncertainty was generally small for monitoring near peak coloration and peak coloration, which was followed by moderate coloration, post-peak coloration and low coloration (Fig. 9b). For uncertainty less than 5 days, the proportions of pixels in both deciduous forests and mixed forests were $60.8 \%, 80.4 \%$, $88.2 \%, 83.5 \%$, and $75.6 \%$ in low coloration, moderation coloration, near-peak coloration, peak coloration, and post-peak coloration, respectively. For uncertainty less than 10 days, the relative proportions were $81.3 \%, 94.1 \%, 98.6 \%, 98.1 \%$, and $94.8 \%$.

\section{Discussion and conclusions}

This paper has demonstrated that the continuous development of foliage senescence can be monitored in real time and forecasted in short term from satellite data in a large spatial coverage. This extends current field observations of fall foliage, which are available in limited plant species and locations, such as the USDA-Forest Service Regional Fall Foliage Sites (http://www.fs.fed.us/news/fallcolors/), forest-ecology networks (http://www.forestecologynetwork.org/), and citizen-scientist fall foliage networks (http://www.foliagenetwork.com/). The result improves our understanding of the temporal and spatial variations in fall foliage developments across various ecosystems, which is particularly important in environmental and weather monitoring and forecasting.

The prototype algorithm proposed was practical for us to monitor and forecast fall foliage coloration phases across various ecosystem. It generated potential NDVI trajectories of senescence development using a pixel-dependent sigmoidal model that is biophysically meaningful and has been widely verified based on field measurements, webcam vegetation indexes, and satellite data (e.g. Birch et al., 1998; Ratkowsky, 1983; Richards, 1959; Richardson et al., 2006; Zhang et al., 2003). This approach was conceptually different from previous forecasting methods that included models based on meteorological data (temperature and photoperiod) (e.g. García-Mozo et al., 2008; Delpierre et al., 2009; Jolly et al., 2005), the autoregressive distributed-lag function of satellite greenness with precipitation and temperature (Ji and Peters, 2004), and the empirical distributions of pixels above a NDVI threshold in an ecoregion (White and Nemani, 2006).

The developed methodology was able to produce both measurements and uncertainties in continuously tracking and forecasting fall foliage colorations. At a given time, a set of potential temporal trajectories was established by combining the available satellite observations with the climatology that provides potential dormancy conditions in the future. The potential trajectories allowed us to monitor the current phenological status and to predict the occurrence of future coloration phases. The trajectories varied with the potential dormancy conditions derived from the climatology and produced statistical uncertainty of the phenological detections. Because the contribution of climatological conditions during the generation of potential trajectories gradually decreased with an increase in satellite observations, the accuracy of foliage coloration monitoring improved correspondingly.

Short-term forecasting could be conducted effectively more than half a month early. The mean absolute error was relatively large for events at the beginning of the senescent phase because there were only limited satellite observations available. Thus, the 
error of forecasting in low and moderate coloration states could be as large as 10 days. In contrast, the error was less than 5 days for the onset of near-peak coloration and peak coloration when compared with field measurements in the Harvard Forests.

The real-time monitoring was also more accurate for late coloration phases than for early phases. The monitoring of fall foliage coloration for 8 years in the Harvard Forests showed that the mean absolute error was less than 3 days for the onset of near-peak coloration, peak coloration and post-peak coloration. However, this error could be larger than 5 days for the onset of low coloration and moderate coloration. Nevertheless, the uncertainty in real-time and near real-time monitoring was generally less than 2 days.

Comparisons with standard fall foliage detections also revealed that the proposed algorithm was robust for real-time monitoring across a large region. The difference was less than 5 days in more than $62 \%$ of mixed and deciduous forests across the northeastern North America region. It was less than 10 days in more than $90 \%$ of the MODIS pixels.

The accuracy of the algorithm developed was influenced by several factors. Testing was conducted using 8-day MODIS NBAR data generated from 16-day observations. The temporal resolution in this dataset could have affected the accuracy of real-time monitoring. Moreover, the accuracy of monitoring could have been influenced by cloud contaminations in the time series of 8-day MODIS data. For example, $27 \%$ of the $1 \mathrm{~km}$ global land pixels were missing at least one 16-day period in 2001 (Zhang et al., 2006). However, this algorithm could be a prototype for real-time monitoring and short-term forecasting for the Visible Infrared Imager Radiometer Suite (VIIRS) and the next generation of Geostationary Operational Environmental Satellites (GOES-R). In particular, the GOES-R observes the surface every $5 \mathrm{~min}$, which could provide a high quality daily vegetation index without cloud contamination.

Finally, it is noted that satellite data monitor the development of fall foliage colorations that represent the vegetation communities within an entire satellite pixel. It is currently impossible to distinguish species-specific fall foliages and to separate tree canopy foliages from understory vegetation. If a pixel contains plants with very different fall foliage statuses, the satellite monitoring represents the overall foliage coloration phases within the pixel, which does not necessarily match well with the coloration in any individual species. However, if a pixel is dominated by species with similar senescent phases, the satellite-monitored foliage phases could represent well the species-specific foliage development (Zhang and Goldberg, 2011). In other words, our current monitoring generally provides the average coloration phases of plant species in a pixel. When reliable species distribution data are available in future, the fall foliage development of specific species could be quantified.

\section{Acknowledgements}

We wish to thank John O'Keefe at the Harvard Forest LTER for providing phenology data, Crystal B. Schaaf for help in MODIS NABAR data, Marco Vargas, Xiwu Zhan, Kevin Gallo, Mark Friedl, and anonymous reviewers for valuable comments. The views, opinions, and findings contained in this study are those of the author(s) and should not be interpreted as an official NOAA or US Government position, policy, or decision.

\section{References}

Asner, G.P., Townsend, A.R., 2000. Satellite observation of El Nino effects on Amazon forest phenology and productivity. Geophysical Research Letters 27 (7), 981-984.

Asner, G.P., Wessman, C.A., Bateson, C.A., Privette, J.L., 2000. Impact of tissue, canopy, and landscape factors on the hyperspectral reflectance variability of arid ecosystems. Remote Sensing of Environment 74 (1), 69-84.
Atkinson, D., Porter, J.R., 1996. Temperature, plant development and crop yields. Trends in Plant Science 1 (4), 119-124.

Birch, C.J., Hammer, G.L., Rickert, K.G., 1998. Improved methods for predicting leaf area and leaf senescence in maize (Zea mays). Australian Journal of Agricultural Research 49, 249-262.

Chambers, J.Q., Fisher, J.I., Zeng, H., Chapman, E.L., Baker, D.B., Hurtt, G.C., 2007. Hurricane Katrina's carbon footprint on U.S. Gulf coast forests. Science 318 (5853), 1107, doi:10.1126/science.1148913.

Delpierre, N., Dufrêne, E., Soudani, K., Ulrich, E., Cecchini, S., Boé, J., Franccois, C., 2009. Modelling interannual and spatial variability of leaf senescence for three deciduous tree species in France. Agricultural and Forest Meteorology 149 (6-7), 938-948.

Fisher, J.I., Mustard, J.F., Vadeboncoeur, M.A., 2006. Green leaf phenology at Landsat resolution: scaling from the field to the satellite. Remote Sensing of Environment $100,265-279$.

Friedl, M.A., Sulla-Menashe, D., Tan, B., Schneider, A., Ramankutty, N., Sibley, A., Huang, X., 2010. MODIS Collection 5 global land cover: algorithm refinements and characterization of new datasets. Remote Sensing of Environment 114, $168-182$.

García-Mozo, H., Chuine, I., Aira, M.J., Belmonte, J., Bermejo, D., Díaz de la Guardia C., Elvira, B., Gutiérrez, M., Rodríguez-Rajo, J., Ruiz, L., Trigo, M.M., Tormo, R. Valencia, R., Galán, C., 2008. Regional phenological models for forecasting the start and peak of the Quercus pollen season in Spain. Agricultural and Forest Meteorology 148, 372-380.

Gu, L., Hanson, P.J., Post, W.M., Kaiser, D.P., Yang, B., Nemani, R., Pallardy, S.G., Meyers, T., 2008. The 2007 eastern US spring freeze: increased cold damage in a warming world? BioScience 58 (3), 253-262.

Hartkamp, A.D., Hoogenboom, G., Gilbert, R.A., Benson, T., Tarawali, S.A., Gijsman A.J., Bowen, W., White, J.W., 2002. Adaptation of the CROPGRO growth model to velvet bean (Mucuna pruriens) II. Cultivar evaluation and model testing. Field Crops Research 78 (1), 27-40.

Herwitz, S.R., 1985. Interception storage capacities of tropical rainforest canopy trees. Journal of Hydrology 77, 237-252.

Huete, A.R., Kamel Didan, K., Shimabukuro, Y.E., Ratana, P., Saleska, S.R., Hutyra, L.R., Yang, W., Nemani, R.R., Myneni, R., 2006. Amazon rainforests green-up with sunlight in the dry season. Geophysical Research Letters 33, L06405 (1-6).

IPCC, 2007. In: Parry, M.L., Canziani, O.F., Palutikof, J.P., van der Linden, P.J., Hanson, C.E. (Eds.), Climate Change 2007: Impacts, Adaptation, and Vulnerability Contribution of Working Group II to the Fourth Assessment Report of the Intergovernment Panel on Climate Change. Cambridge University Press, Cambridge, p. 976 pp.

Ji, L., Peters, A.J., 2004. Forecasting vegetation greenness with satellite and climate data. IEEE Geoscience and Remote Sensing Letters 1 (1), 10.1109/LGRS. 2003.821264.

Jolly, W.M., Neman, R., Running, S.W., 2005. A generalized, bioclimatic index to predict foliar phenology in response to climate. Global Change Biology 11, 619-632, doi:10.1111/j.1365-2486.2005.00930.x.

Jonsson, P., Eklundh, L., 2004. TIMESAT-A program for analyzing time-series of satellite sensor data. Computers \& Geosciences 30, 833-845.

Karlsen, S.R., Ramfjord, H., Hogda, K.A., Johansen, B., Danks, F.S., Brobakk, T.E., 2009. A satellite-based map of onset of birch (Betula) flowering in Norway. Aerobiologia 25, 15-25, doi:10.1007/s10453-008-9105-3.

Keatinge, J.D.H., Qi, A., Wheeler, T.R., Ellis, R.H., Summerfield, R.J., 1998. Effects of temperature and photoperiod on phenology as a guide to the selection of annual legume cover and green manure crops for hillside farming systems. Field Crops Research 57 (2), 139-152.

Kovalskyy, V., David, P., Roy, D.P., Zhang, X., Ju, J., 2012. The suitability of multitemporal web-enabled Landsat data NDVI for phenological monitoring - a comparison with flux tower and MODIS NDVI. Remote Sensing Letters 3 (4), 325-334.

McNulty, S.G., 2002. Hurricane impacts on US forest carbon sequestration. Environmental Pollution 116 (Suppl. 1), doi:10.1016/S0269-7491(01)00242-1.

Myneni, R.B., Keeling, C.D., Tucker, C.J., Asrar, G., Nemani, R.R., 1997. Increased plant growth in the northern high latitudes from 1981 to 1991. Nature 386 698-702.

Liang, L., Schwartz, M.D., Fei, S.L., 2011. Validating satellite phenology through intensive ground observation and landscape scaling in a mixed seasonal forest. Remote Sensing of Environment 115, 143-157.

Nemani, R., Hashimoto, H., Votava, P., Melton, F., Wang, W., Michaelis, A., Mutch, L., Milesi, C., Hiatt, S., White, M., 2009. Monitoring and forecasting ecosystem dynamics using the Terrestrial Observation and Prediction System (TOPS) Remote Sensing of Environment 113, 1497-1509.

Parmesan, C., Yohe, G., 2003. A globally coherent fingerprint of climate change impacts across natural systems. Nature 421, 37-42.

Ratkowsky, D.A., 1983. Nonlinear Regression Modeling-A Unified Practical Approach. Marcel Dekker, New York, pp. 61-91.

Reed, B.C., Brown, J.F., VanderZee, D., Loveland, T.R., Merchant, J.W., Ohlen, D.O. 1994. Measuring phenological variablity from satellite imagery. Journal of Vegetation Science 5, 703-714.

Richards, F.J., 1959. A flexible growth function for empirical use. Journal of Experimental Botany 10, 290-300.

Richardson, A.D., Bailey, A.S., Denny, E.G., Martin, C.W., O’Keefe, J., 2006. Phenology of a northern hardwood forest canopy. Global Change Biology 12, 1174-1188.

Román, M.O., Schaaf, C.B., Woodcock, C.E., Strahler, A.H., Yang, X., Braswell, R.H., Curtis, P., Davis, K.J., Dragoni, D., Goulden, M.L., Gu, L., Hollinger, D.Y., Kolb, T.E. Meyer, T.P., Munger, J.W., Privette, J.L., Richardson, A.D., Wilson, T.B., Wofsy, S.C., 
2009. The MODIS (Collection V005) BRDF/albedo product: assessment of spatial representativeness over forested landscapes. Remote Sensing of Environment 113, 2476-2498.

Schaaf, C.B., Gao, F., Strahler, A.H., Lucht, W., Li, X., Tsang, T., Strugnell, N., Zhang, X.Y., Jin, Y., Muller, J.P., Lewis, P., Barnsley, M., Hobson, P., Disney, M., Roberts, G., Dunderdale, M., Doll, C., d'Entremont, R.P., Hu, B., Liang, S., Privette, J.L., 2002. First operational BRDF, albedo and nadir reflectance products from MODIS. Remote Sensing of Environment 83, 135-148.

Schwartz, M.D., 1998. Green-wave phenology. Nature 394, 839-840.

Wan, Z.M., Zhang, Y.L., Zhang, Q.C., Li, Z.L., 2002. Validation of the landsurface temperature products retrieved from Terra Moderate Resolution Imaging Spectroradiometer data. Remote Sensing of Environment 83, 163-180.

White, M.A., Nemani, R.R., 2006. Real-time monitoring and short-term forecasting of land surface phenology. Remote Sensing of Environment 104, 43-49.

White, M.A., Thornton, P.E., Running, S.W., 1997. A continental phenology model for monitoring vegetation responses to interannual climatic variability. Global Biogeochemical Cycles 11, 217-234.
Zhang, X., Goldberg, M.D., 2011. Monitoring fall foliage coloration dynamics using time-series satellite data. Remote Sensing of Environment 115 (2), 382-391, doi:10.1016/j.rse.2010.09.009.

Zhang, X., Friedl, M.A., Schaaf, C.B., 2006. Global vegetation phenology from MODIS evaluation of global patterns and comparison with in situ measurements. Journal of Geophysical Research 111, G04017, doi:10.1029/2006JG000217.

Zhang, X., Friedl, M.A., Schaaf, C.B., Strahler, A.H., Hodges, J.C.F., Gao, F., Reed, B.C. Huete, A., 2003. Monitoring vegetation phenology using MODIS. Remote Sensing of Environment 84, 471-475.

Zhang, X., Friedl, M.A., Schaaf, C.B., Strahler, A.H., Liu, Z., 2005. Monitoring the response of vegetation phenology to precipitation in Africa by coupling MODIS and TRMM instruments. Journal of Geophysical Research-Atmospheres 110, D12103.

Zhang, X., Goldberg, M., Tarpley, D., Friedl, M., Morisette, J., Kongan, F., Yu, Y., 2010 Drought-induced vegetation reduction in Southwestern North America. Environmental Research Letters 5, 024008, doi:10.1088/1748-9326/5/2/024008.

Zhang, X., Tarpley, D., Sullivan, J., 2007. Diverse responses of vegetation phenology to a warming climate. Geophysical Research Letters 34, L19405, doi:10.1029/2007GL031447. 